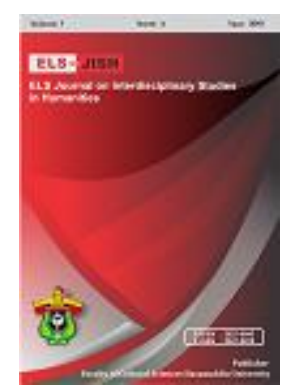

\title{
ELS-JISH
}

ELS Journal on Interdisciplinary Studies on Humanities

Volume 2 Issue 2, 2019

ISSN (print) : 2621-0843

ISSN (online) : 2621-0835

Homepage : http://journal.unhas.ac.id/index.php/jish

\section{The Usage of Combined Components of Verbal L, Vocal and Visual (3-V Components) of Children in Daily Conversation: Psycholinguistic Observation}

\author{
Amanda Pratiwi Ismail ${ }^{1}$ \\ ${ }^{1}$ Amanda.p.ismail@gmail.com
}

\begin{abstract}
This study aims at explaining, describing and a study of research about the pshycholinguistic, in order to know what kind of the usage of combined components of 3-V (Verbal language 7\%, Intonation (Vocal) $38 \%$, Body language (Visual) $55 \%$ by childrens of age in daily conversation. Research conducted qualitative and quantitative descriptive method research with using triangulation techniques to data collection. There are interview, field research or observation and literature review or document. The results of the study showed that competence and linguistics performance by childrens of age in daily conversation affected by three pshycholinguistic streams, that is behaviouristic pshycholinguistic, cognitive pshycholinguistic and mentalistic pshycholinguistic in improve the delivery of meaning with using combined components of 3-V (Verbal language 7\%, Intonation (Visual) 38\%, Body language (Visual) $55 \%$ in daily conversation. Step and method which is used for improve competence and performance linguistics by childrens of age in daily conversation, that is with how to improve their the affected of three pshycholinguistic streams; behaviouristic pshycholinguistic, cognitive pshycholinguistic and mentalistic pshycholinguistic is with the childrens needs to learn and study languages through the pattern as follows: 1. All components, system and language skills are learned in integrated manner. 2. Language learning is done naturally and directly in an authentic context. 3. Language learning is done in stages according to their needs. 4. Language learning is done through trial-error strategic. Skilled at dialogue with interviewing various of the professional of type, the importance of pretend play through sociodramatic play for the affected cognitive pshycholinguistic development by the childrens, behaviouristic pshycholinguistic and their mentalistic pshycholinguistic.
\end{abstract}

Keywords: Pshycholinguistic, Linguistic Acquisition, Trial Error, Pretend Play, Sociodramatic Play.

How to cite: Ismail, A.P. (2019). The Usage of Combined Components of Verbal L, Vocal and Visual (3-V Components) of Children in Daily Conversation: Psycholinguistic Observation. ELS Journal on Interdisciplinary Studies in Humanities, 2 (2), 291-301.

\section{Introduction}

Language, it is an important aspect which is needed and used in everyday life for interact and communicate, to create beauty, to express thought either to individuals or another group, menyatakan perasaan-perasaan kepada individu

\footnotetext{
${ }^{1,}$ Hasanuddin University, Indonesia
} 
ataupun kelompok lain, to get the knowledge and culture from generation to generation. Examining the language is not possible without examine the human user.

According to Garnham explained "Psycholinguistics is the study of a mental mechanisms that make it possible for people to use language. It is scientific discipline whose goal is a coherent theory of the way in which language is produced and understood" (Ahmadi, 2015). Therefore, psycholinguistics theory can describe and understand psychological processes that take place if someone says the sentences who hear it when communicating. That language ability is commonly obtained by humans not only verbally, but also nonverbal behaviour, it is an intonation of voice (Vocals) and the most important is the body language (Visual).

Albert Mehrabian (Professor of Emeritus at Psychology UCLA), known for its publication of the importance of the relationship between verbal and nonverbal messages. It is Intonation (Vocal) and body language (Visual). His findings regarding the message inconsistency regarding feelings and attitudes have been quoted through various seminars in various parts of the world and are known as Law 7\% $38 \%-55 \%$. Mehrabian gave a clear statement on this matter as follows:
a. $7 \%$ of the meaning comes from spoken words
b. $38 \%$ meaning comes from paralinguistic (how to say words or sound intonation).
c. $55 \%$ comes from facial expressions or body language.



\section{Elements of Personal Communication \\ - $7 \%$ spoken words \\ - $38 \%$ voice, tone \\ - $55 \%$ body language}

Figure 1. Albert Mehrabian's 7-38-55\% Rule (Belludi. 2008. Rule Personal Communication)

Can increase and multiply the meaning of messages delivered when using 3-V components at once, Verbal (words), Vocal (intonation) and Visual (body language) through the title "The Usage of combined components of 3-V (Verbal language $7 \%$, Intonation (Vocal) 38\%, Body language (Visual) 55\% by childrens of age in daily conversation: Psycholinguistic Observation".

\section{Theory and Method}

According to Garnham explained "Psycholinguistics is the study of a mental mechanisms that make it possible for people to use language. It is scientific discipline whose goal is a coherent theory of the way in which language is produced and understood" (Ahmadi, 2015). There are three streams in psycholinguistics, it is the Behaviouristic Psycholinguistics is children learn a language and they learn more than is available to them through their own environment, Cognitive Psycholinguistics is cognitive and linguistic skills that are actually innate from birth and Mentalistic 
Psycholinguistics is that humans have knowledge and ideas in their minds. These ideas are entirely obtained from experience (the opinion of the empiricist) or these ideas have existed in mind since birth (rational ideas).

Competence is the knowledge of linguistic abilities owned by language users, performance that refers to cognitive processes, processes of awareness and understanding, skills and strategies used by the language user in actual use of linguistic knowledge.

As Alan Cruttenden said in his book that "Intonation involves the occurrence of recurring pitch patterns, each of which is used with a set of relatively consistent meanings, either on single words or groups of words varying length. Intonation may indicate a discoursal meaning like inviting a listener to make a contribution to the conversation, or an attitudinal meaning like being condescending". (Cruttenden, 1986).

Likewise said (Hayakawa, 1978: 62) in his book "We have seen, language is also used for the direct expression of the feelings of the speaker. And the first affective elements in speech, as we have seen, is the tone of voice - it's loudness or softness, its pleasentness or unpleasentness, its variations in volume and intonation during the course of utterance. And another affective element in language is rhythm. Ryhthm is the name we give to the effect produced by the repetition of auditory (or kinesthetic)stimult at fairly reguler intervals". It is an affective and important elements results are as much as $38 \%$ it is from Intonation of voice (Vocal).

In his book "Louder than Words" (Navarro, 2010) said "The world is constantly communicating nonverbally. Our body movements, our facial expressions, how we speak, how we show our emotions, how we dress, the posseions we favor, our concious and unconcious behaviour and attitudes - even our enviroments - are all communicating nonverbally." Likewise (Anthony Robbins, 1999) in the body language module and intonation said "You can not NOT communicate", and it is more important and affective element is results are as much as $55 \%$ of body language (Visual),

This research uses descriptive qualitative and quantitative method in order to obtain an accurate data to explain qualitative descriptively of the usage of combined components of 3-V (Verbal language 7\%, Intonation (Vocal) 38\%, Body language (Visual) $55 \%$ by childrens of age in daily conversation: Pshycholinguistic Observation.

\section{Findings}

Data in these findings are classified by the categorization of daily conversation speech acts such as the strategy of asking by giving statements, the strategy of introducing themselves, the strategy to make statements, the strategy of expressings, the strategy of giving an orders, the strategy of making questions, the use as follows.

\section{Data 1.}
A : “Janganko banyak bicara,e!, ini juga Wandi e!, ribut sekali!"
"Kamu jangan banyak bicara!, Kamu juga wandi! Berisik sekali!"
"Don't talking too much! You too wandi! Very noisy!" 
"Pak, sudahmi pak!".

"Sir, it's already sir!".

“ey, diam sayko kodong.."

"Halo, tolong kamu bisa diam kasihan.."

"Hello, I'm sorry.. be quiet, ...please ..."

B : “Eh!,,Masih ingat pelajaran itu hari?”

"Semuanya,,Masih ingat pelajaran hari yang lalu?"

"Everyone ... Do you still remember the lesson yesterday?"

A \& siswa lainnya : "Masih!!”.

"Masih!"

"Yes!"

Context: SPEAKING in the conversation above is a situation in five grade classroom at the time of entering the study time and there is a rest time after the break and the bell has sounded. Involving all students and teachers with a rather noisy situation that makes one student a little annoyed, ask and tell friends all around in the classroom. The child $A$ has the competence to use a variety of utterances to his friend, so his utterances performance of the strategy of asking to his friends.

The Competence and Perfomance : As is known Competence is the knowledge of linguistic abilities owned by language users, while performance that refers to cognitive processes, processes of awareness and understanding, skills and strategies used by the language user in the use of linguistic knowledge actually. Competence and perfomancy by children of age is based on the following three streams of psycholinguistics:

Behaviouristic Psycholinguistics : Children learn a language so they learn more than is available to them through their own environment. The competency or linguistic ability of the speaker or five grade child at the age of 10 years old is influenced by his behaviouristic or through his own environment, not only does the speaker speak his linguistics from the acquisition of his first language or his mother tongue, but also from friends in his own school environment, it is an Indonesia Language, speak Indonesian language with Makassar language dialect. The language he learned by looking at the original grammar of his parents.

Cognitive Psycholinguistics : Psycholinguists develop cognitive and linguistic skills that are actually innate at birth. The Competence is the language skills of children of age 10 years old apart from being influenced by behaviouristic psycholinguistics which is language learned by looking at the original grammar of their parents and the environment that surrounded, the linguistic competence is also influenced by cognitive psycholinguistics which is linguistic abilities that are innate from birth and constructive. From the language learned by looking at the original grammar of his parents, then the child composes or constructs a new grammar that is simplified by the innovations he made himself and by linguistic means that act to help children produce understandable utterances so produced the perfomances 
which is not only influenced by Behaviouristic psycholinguistics, but also his Cognitive psycholinguistics with tactics found to form and pronounce a sentence described from thoughts, opinions, desires, ideas, messages adapted to semantic structures produce grammar, syntactic and phonological forms that correspond to filtered semantic structures. The semantic structure in the linguistic performance of a 10 year old child who describes a desire by formulating and saying a sentence "Janganko banyak bicara,e!, ini juga Wandi e!, ribut sekali!" "Kamu jangan banyak bicara!, Kamu juga Wandi! Berisik sekali!"."Don't talk much! You too Wandi! Very noisy!".

\section{"Jangan ko banyak bicara,e!, ini juga Wandi e!', ribut sekali!"”}

\section{Verb Pronomina Adj Noun Particle Injection Adj}

The linguistic performance in the form of The strategy of asking his friends by expressing the statement that his friend is noisy so that based on cognitive psycholinguistics the tactics that are found in the form of desires described from the semantic structure produces a strategy of syntactic forms of asking to his friend. Likewise with the formulation of sentences made as the follows "ey, diam sayko kodong.." "Halo, tolong kamu bisa diam kasihan.." "Hello, I'm sorry.. be quiet, ...please ..." The strategy of an asking sentence with using asking for help of words.

\section{"ey, diam say ko kodong.." \\ Verb Pronomina}

Mentalistic Psycholinguistics

: That humans have knowledge and ideas in their minds. These ideas are entirely obtained from experience (the opinion of the empiricist) or these ideas have existed in mind from birth (rational ideas). The linguistic competence and performance of children of age 10 year old elementary school students who are influenced by psycholinguistic behaviouristic, cognitive psycholinguistics, and even Mentalistic psycholinguistics which is the competence and linguistic performance produced by the child, has knowledge and ideas in his mind since birth and is obtained from his experience. In addition to asking strategies that child formulate, his also inserting the word "kodong.." "kasihan.." "I'm Sorry..." that is linguistic means which is the child's strategy or speaker in producing easy-tounderstand utterances in the form of a listener's strategy of speech-wave fragments of information, which determines the linguistic structure. The listener can also get or know from the mood and other characteristics of the speaker. It can be seen from the competence and linguistic performance of 10-year-old children that the verbal language results are as much as $7 \%$.

Intonation (Vocals) 38\%: The competence and performance of children of age 10 years old are influenced by several psycholinguistics is behaviouristic psycholinguistic, cognitive psycholinguistics and mentalistic psycholinguistics, so that it produces grammar, syntactic forms that correspond to their semantic structure and speech tools are arranged by nerves in accordance with phonological patterns of sentences, so that sound waves are produced.

The child or speaker has desires and ideas and then makes that desires and become systematic phonetic images that create speech marks of sound waves that touch the ears of listeners. Like the intonation of the following sentences: 


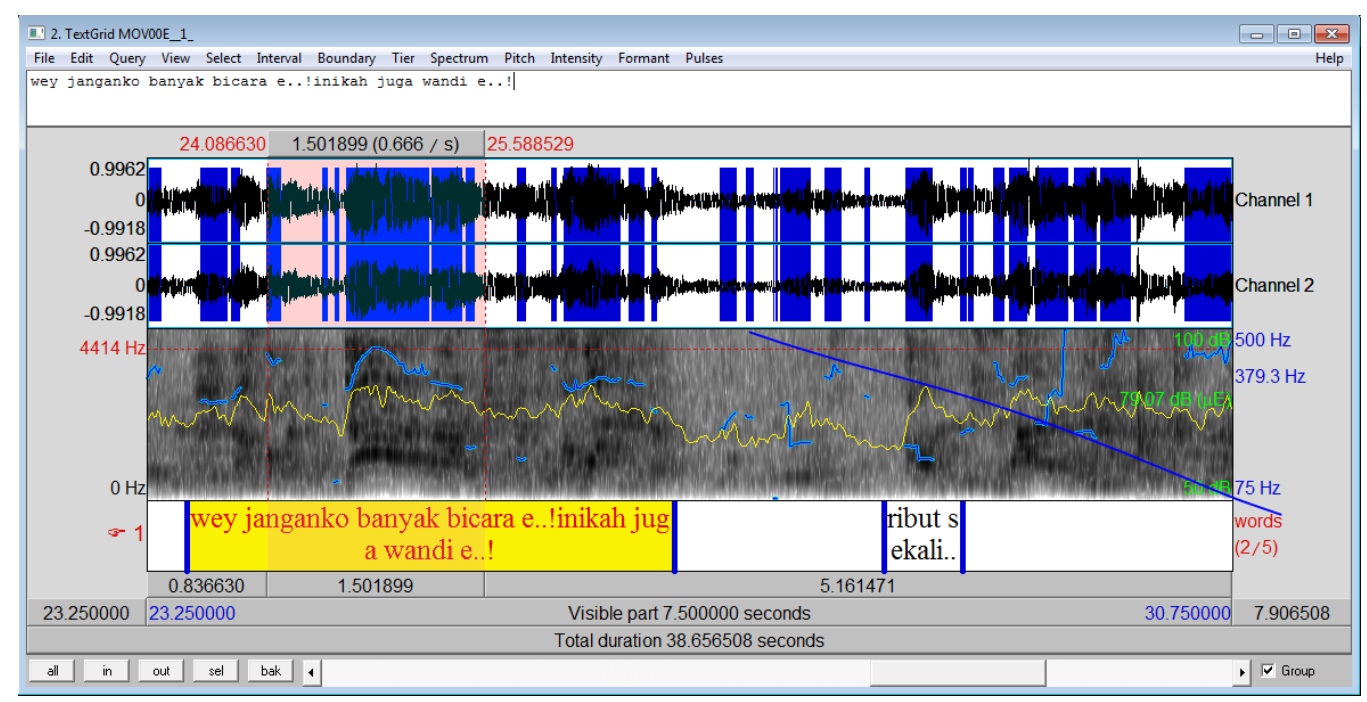

Figure 2. Intonation scheme of utterances

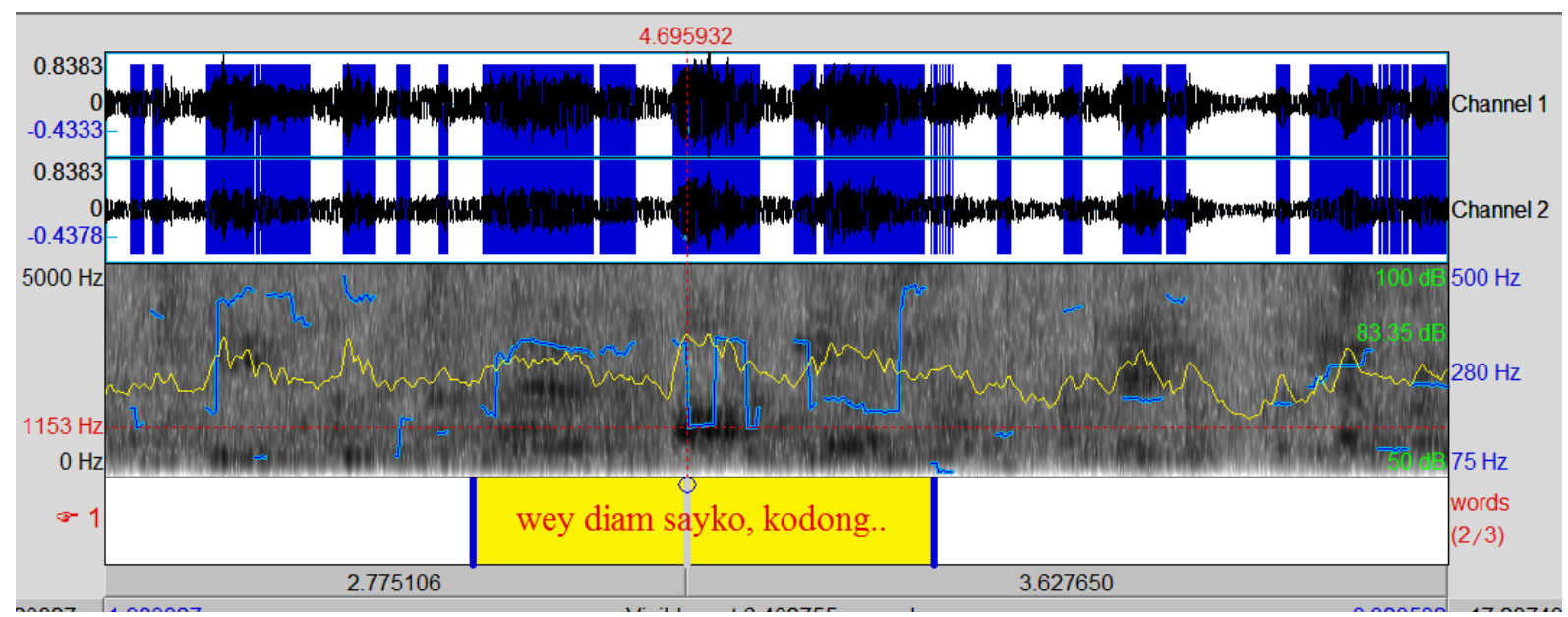

Figure 3. Intonation scheme of utterances

According to Alan Cruttenden (1986) "Intonation involves the occurrence of recurring pitch patterns, each of which is used with a set of relatively consistent meanings, either on single words or groups of words varying length. Intonation may indicate a discoursal meaning like inviting a listener to make a contribution to the conversation, or an attitudinal meaning like being condescending". The Perfomance on sentence of utterances spoken by children, through intonation (vocals) the meaning delivered results are as much of $38 \%$ shows an attitudinal meaning like being condescending in the sentence of figure 3 .

According to Verhaar (2012) to understand suprasegmental sounds can be seen from the acoustics angle. There are two acoustic properties that play a role in suprasegmental sounds "frequency" and "amplitude". The frequency is the vibration of the air, determining the height of the tone, while the amplitude of the width of the air waves is the same as the loudness of the sound. If we say sentences, the tone of voice changes, according to the high and low the tone. The linguistic performance of child produces syntactic form which is the meaning of asking for help, according to phonetic scheme that shows the frequency of the words for an asking for help with lowering the tone of frequency intonation shows results are as much $1153 \mathrm{~Hz}$ of 5000 
$\mathrm{Hz}$ height of the tone of the frequency, while the width of the air waves or it is known as the amplitude shows results $81,19 \mathrm{~dB}$ of $100 \mathrm{~dB}$. Intonation can also be caused by other elements that show sadness, or feeling happy and other feelings. Can be seen in picture 2. Intonation of the low frequency of the tone shows results as much as $1719 \mathrm{~Hz}$ of $5000 \mathrm{~Hz}$, while the width of the air waves or it is known as the amplitude shows results 70,78 dB of $100 \mathrm{~dB}$ pada kata "kodong.." "kasihan.." "I'm sorry...". The child's strategy in asking for help by lowering the frequency of his voice and thickening his amplitude can be captured by the listener's speech through sound waves produced so that the listener changes sound into meaning indicating the element of sadness in his intonation, so that in communicating elements in to shows the meaning of the message in conversation by children of age 10 years old, the competence and linguistic performance in the form of words or syntactic forms in the strategy of asking for help shows results are as much as $7 \%$ is supported and supporting each other by its intonation as much as $38 \%$ which is in addition to lowering the word of request / asking for help but also in his strategy to shows his sad mood. Likewise (Hayakawa, 1978: 62) in his book said "We have seen, language is also used for the direct expression of the feelings of the speaker. And the first affective elements in speech, as we have seen, is the tone of voice - it's loudness or softness, its pleasentness or unpleasentness, its variations in volume and intonation during the course of utterance. And another affective element in language is rhythm. Ryhthm is the name we give to the effect produced by the repetition of auditory (or kinesthetic) stimult at fairly reguler intervals". The importance of intonation in language is one of the most effective elements results are as much as $38 \%$. Then he said "in addition to tone of voice and rhythm, another extremely important affective element in language is the aura of the feelings, pleasant or unpleasant, that surrounds practically all words. It will be recalled that a distinction was made between denotations (or extential meaning), pointing of things, and connotations (or intensional meaning), consisting of "ideas", "notions", "concepts", and feelings suggested in the mind. These connotations can be divided into two kinds, the informative and the affective." It can be seen the competence and the linguistic performance of 10 years old in shows meanings in daily conversation, especially the intonation or sound waves produced in picture 1. On Intonation schemes there are high-frequency tones in the word "bicara" [BICARA]" "TALKING" indicating from low and then going up increase then decreases at the end of the word $3249 \mathrm{~Hz}-$ $4580 \mathrm{~Hz}-3715 \mathrm{~Hz}$ of $5000 \mathrm{~Hz}$ the width of the air waves or it is known as the amplitude shows results $80,37 \mathrm{~dB}-77,32 \mathrm{~dB}-77,61 \mathrm{~dB}$ of $100 \mathrm{~dB}$. Can be seen in the picture below:

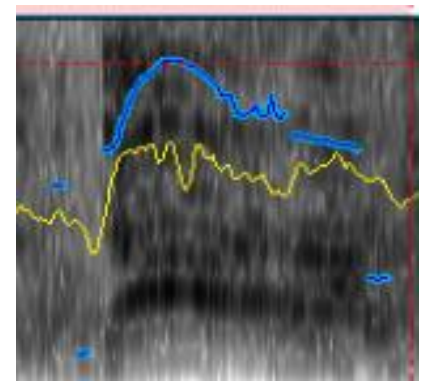

Figure 4. Rhythme by words "Bicara" "Talking" 
The most effective delivery of meaning elements in conversation or communicating result as much as $38 \%$ is Intonation (Vocals) like as said Albert Mehrabian, The presence of rythme in words that are perfomance by child, variations in volume when the child speaks on one of the main words that are important in the strategy skills on requested sentence.

Based on various theories about previous intonation, not only said by Cruttenden, Hayakawa but also in his book Verhaar, intonation is results are as much as $38 \%$ of the important elements in the formation of meaning so that it can speak and deliver the messages more effectively.

The competence and performance linguistic of children of age 10 years old by using $55 \%$ of body language components as follows.

\section{Body Language $55 \%$}

Based in his book "Louder than Words" (Navarro,2010) said "The world is constantly communicating nonverbally. Our body movements, our facial expressions, how we speak, how we show our emotions, how we dress, the posseions we favor, our concious and unconcious behaviour and attitudes - even our enviroments - are all communicating nonverbally." While in body language module by (Anthony Robbins, 1999) said "You can not NOT communicate" means results as much as $55 \%$ effective elements of the delivery of message is the body language.

Ekman et al. (1987) defined six emotions as universal (sadness, happiness, anger, surprise, fear, disgust, also combined with contempt), common among all humans, independently of culture or origin. Nowadays, this theory is questioned. If it is generally accepted that these six emotions are innate for a part, new studies show that culture can modulate FE production (Elfenbein et al., 2007).

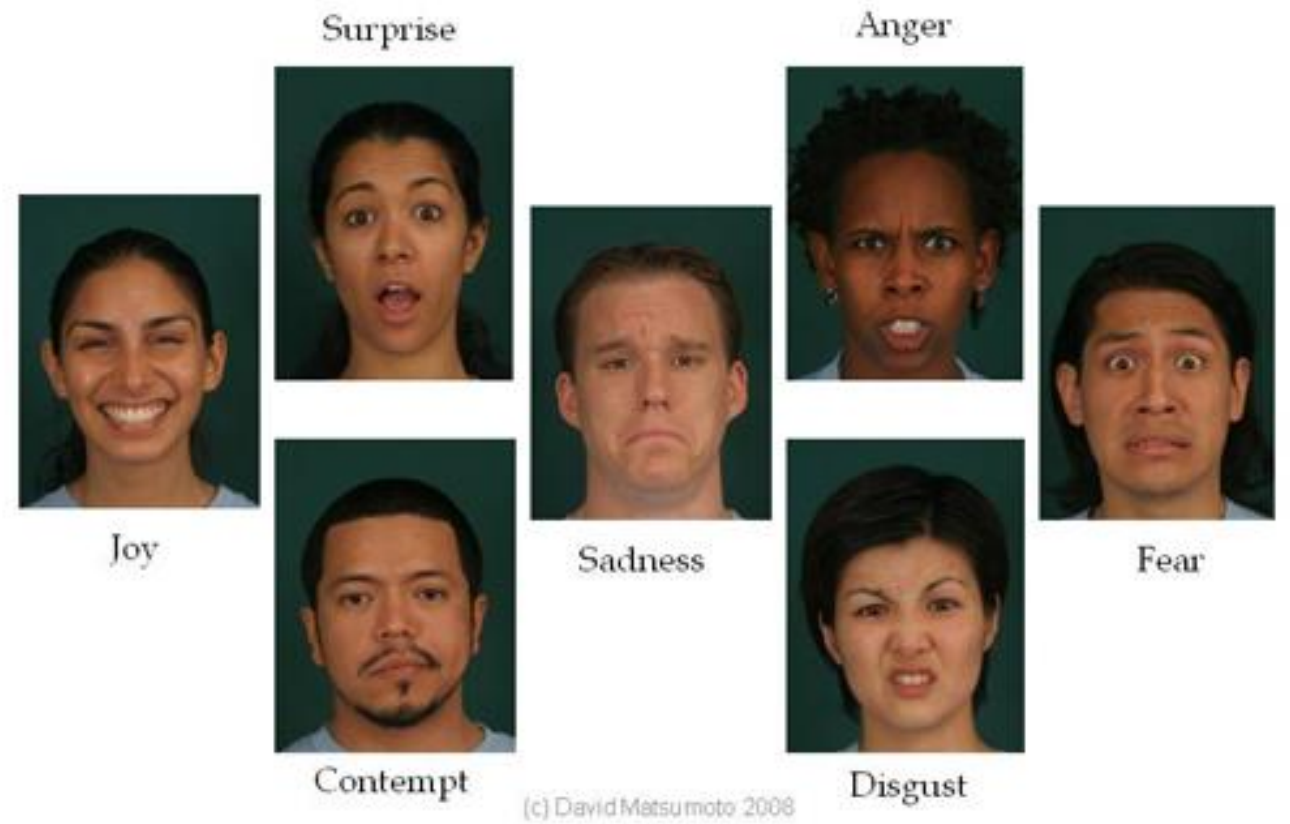

Figure 5. The Seven Basic Emotions and their Universal Expressions.

Based on the competence and linguistic performance of children of age 10 years old in five grade, it is influenced by starting from behaviouristic 
psycholinguistics, cognitive psycholinguistics to mentalistic psycholinguistics, not only from syntactic forms in speech utterances (Verbal language) is produced, intonation (Vocal) but also body language (Visual). The delivery of message in effective elements of communication is body language of facial expression. The child's facial expression shows not only in picture 5 . but also shows in picture 6 . one of the facial expressions from the six basic emotion universal expression shows anger. Differently with facial expressions that shows in picture 7 . The emotion or feeling express shows sadness. The facial expression of children of age 10 years old as follows.

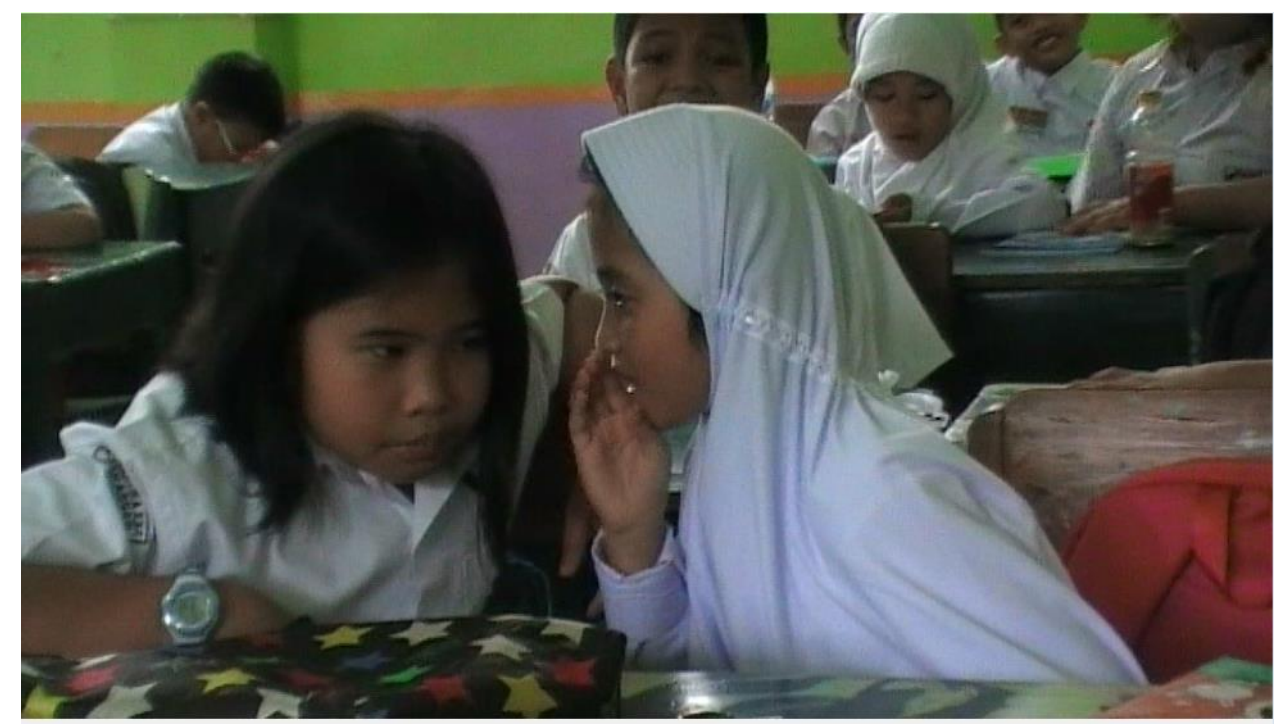

Figure 6. Facial Expression of Anger.

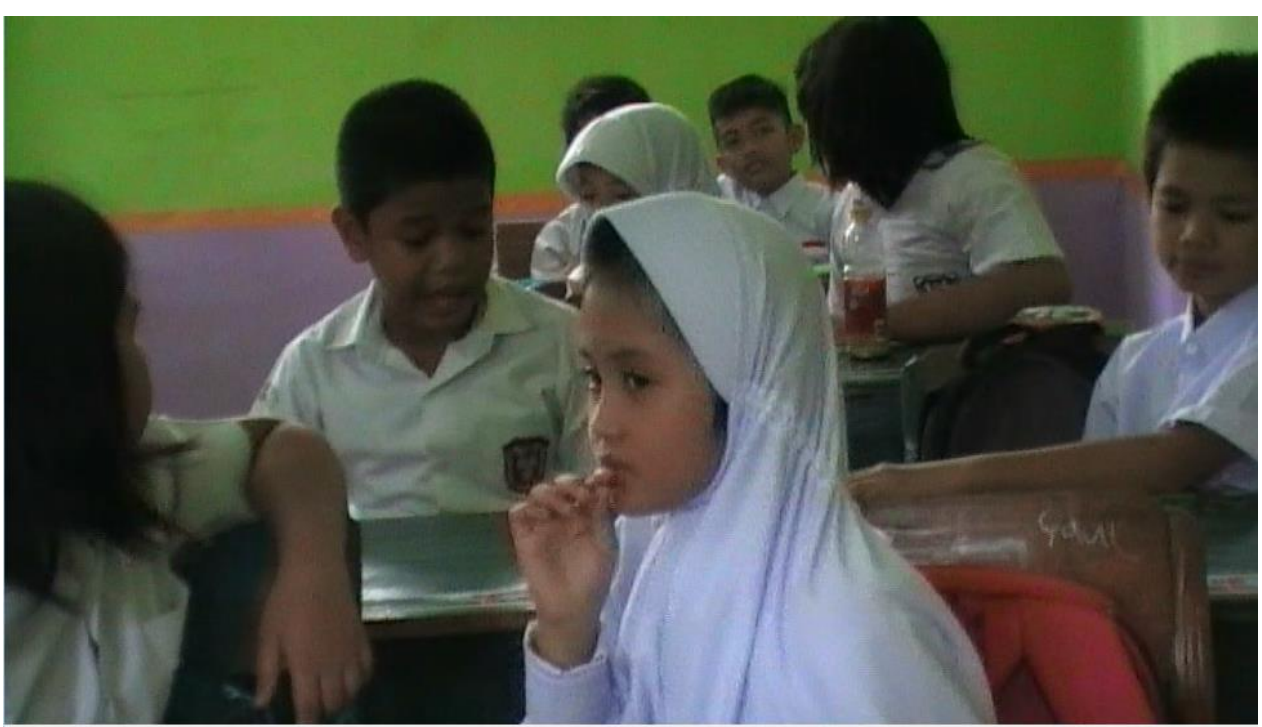

Figure 7. Facial Expression of Anger. 


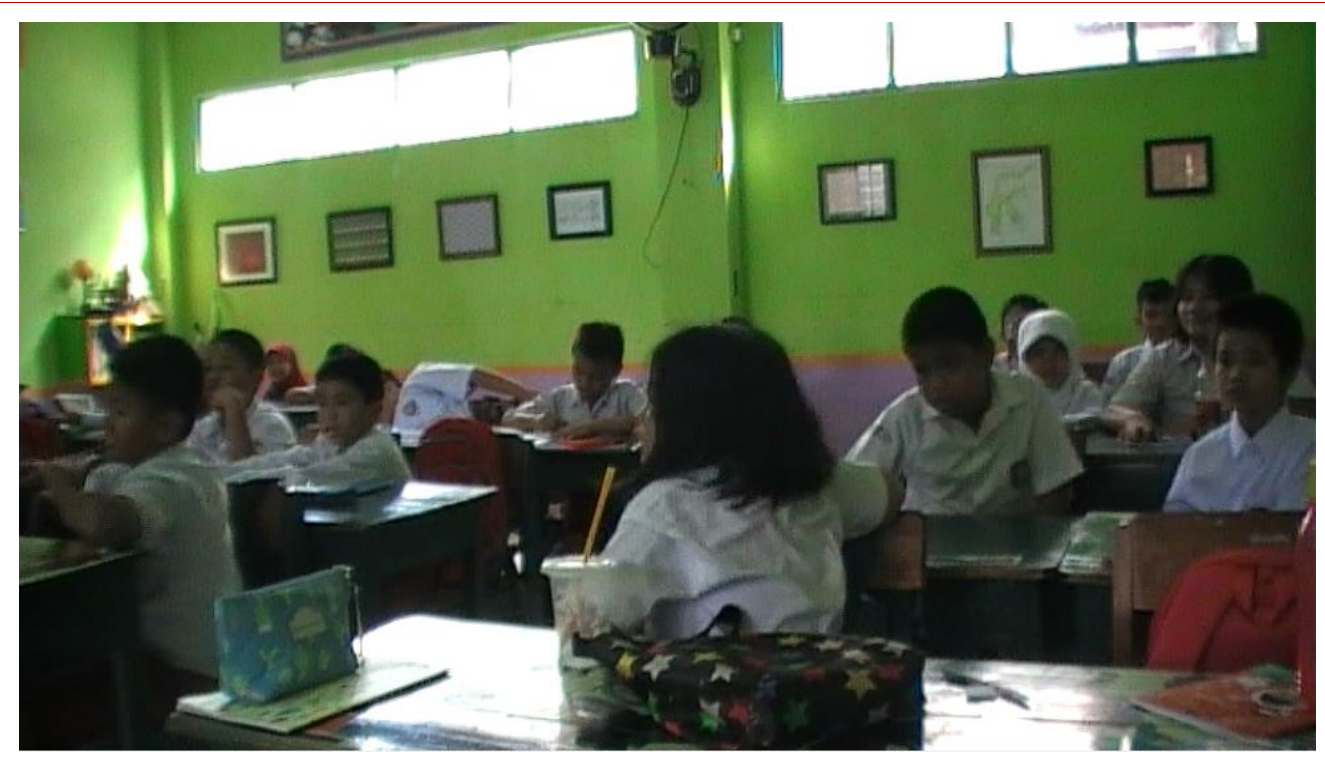

Figure 7. Facial Expression of Sadness

\section{Conclusion}

Based on the results of the analysis and findings of the usage of combined components of 3-V (Verbal language 7\%, Intonation (Vocal) 38\%, Body language (Visual) $55 \%$ by childrens of age in daily conversation: Pshycholinguistic Observation, Language, it is an important aspect which is needed and used in everyday life for interact and communicate, to create beauty, to express thought either to individuals or another group, express feelings to individuals or other groups, to get the knowledge and culture from generation to generation. Examining the language is not possible without examine the human user, it is known as Psycholinguistic. How to use language by increasing the delivery of meaning which is an important element of a combination of $3-\mathrm{V}$ components $(7 \%$ Verbal Language, intonation (vocals) $38 \%$, body language (visual) $55 \%$ ) in daily conversations by children of age, from the description that has been described, it can be seen that linguistic competence and performance in daily conversations by children of age are influenced by three streams of psycholinguistics is behaviouristic psycholinguistic, cognitive psycholinguistics, mentalistic psycholinguistics through linguistic competence and performance of children in order to delivering the meaning of the message by using a combination of $3-\mathrm{V}$ components (7\% Verbal language, $38 \%$ intonation (Vocal), 55\% body language (Visual). After linguistic competence and performance or the use of combined components $3-\mathrm{V}(7 \%$ Verbal, $38 \%$ intonation (vowel), body language / body language (visual) 55\%. After the competence and linguistic perfomance or the usage of combined components of 3-V (Verbal language $7 \%$, Intonation (Vocal) $38 \%$, Body language (Visual) $55 \%$, as well as method that used to increase and improve the competence and linguistic performance in daily conversation by children of age is exactly with the way to improve and increase the influence of behaviouristic psycholinguistic, cognitive psycholinguistics, mentalistic psycholinguistics which is the children learn and study language through the pattern or path as follows : 1. All language components, systems and skills are studied in an integrated manner. 2. Language learning is done naturally and directly in an authentic context. 3. Language learning is done in stages, according to their needs. 4. Learning Language is done through a trial strategy (Trial-Error) and other 
strategies. Another method is to be skilled in dialogue by interviewing various professional groups, besides the importance of pretend play through sociodramatic play to develop the influence of cognitive psycholinguistics on children, behaviouristic psycholinguistics and mentalistic psycholinguistics.

\section{References}

Ahmadi, A. (2015). Dasar-Dasar Psikolinguistik.Jakarta: Prestasi Pustaka.

Belludi, N. (2008). Rule Personal Communication. Diakses 19 oktober 2016 (http://www.rightattitudes.com/2008/10/04/7-38-55-rule-personalcommunication/).

Cruttenden, A. (1986). Intonation. Cambridge textbooks in linguistics.

Children Facial Expression Production: Influence of Age, Gender, Emotion Subtype, Elicitation Condition and Culture. Diakses 28 agustus 2018. (https://www.frontiersin.org/articles/10.3389/fpsyg.2018.00446/full).

Hayakawa,S.i. (1978). Language in Thought And Action. Unites states of America: Harcourt Brace Jovanovich, Publishers.

Navarro, J. (2010). Louder Than Words. New York: Harper Collins Publisher.

Verhaar, J.W.M. (2012). Asas-Asas Linguistik Umum. Yogyakarta: Gadjah Mada University Press. 